\title{
Developing speaking competences in technical English for Spanish civil engineering students
}

\author{
Romero de Ávila Serrano, Vicente ${ }^{a}$; Díaz García, Sarai ${ }^{a}$; Asensio Sánchez, Laura \\ Lozano Galant, José Antonio ; Moyano Enríquez de Salamanca, María Amparo'; \\ Porras Soriano, Rocío ${ }^{a}$; Poveda Bautista, Elisa ${ }^{a}$; Ruiz Fernández, Rita ${ }^{a}$; Sánchez \\ Ramos, David ${ }^{a}$; Sánchez-Cambronero García-Moreno, Santos ${ }^{\mathrm{a}}$; Tarifa Crespo, \\ Manuel Agustín ; Yustres Real, Ángel ${ }^{\text {; }}$ Castillo Sanchez, Carmen ${ }^{\text {a }}$
}

${ }^{a}$ Department of Civil and Building Engineering, University of Castilla-La Mancha, Spain.

\begin{abstract}
Traditionally, Spanish schools of civil engineering provide their students a class on "Technical English" in order to develop their language skills. However, this class does not cover all the skills that the student would need in the labor market and mainly focuses in the reading and writing skills, and in a lower degree in the speaking and listening ones. This paper proposes a series of innovative and informal training activities (cine-forum on technical civil engineering topics and role playing on real professional situations) that allow Spanish civil engineering students to develop English skills that can rarely be worked in the classroom (i.e. speaking, negotiating and conversing), encouraging debate, participation, and fostering their selfconfidence to speak about technical-English topics in public. Although the students' level of English is much lower than expected, they all agree on the importance of technical English for their future career. The results also show the students' lack in skills that are difficult to train in regular classes (speaking and talking). Consequently, this situation would require to provide complementary activities like the ones suggested in this project in order to develop these skills and increase the students' demand for engineering classes taught in English.
\end{abstract}

Keywords: English; language competences; speaking; civil engineers; UCLM. 


\section{Introduction}

Although it has been common in Spain that undergraduates and graduates in science and engineering should study some classes and contents by reading textbooks in English, the Bachelor Degree in Civil Engineering at the University of Castilla-La Mancha (Spain) is completely taught in Spanish. In fact, the ratio of engineering classes taught in English by the Spanish universities is far from the ones of foreign universities as KTH in Sweden, Øsfold University in Norway, Aalto University in Finland, or Delft University in the Netherlands, where most of the classes are taught in English. In the last few years, the Bologna Process for higher education and the Spanish economic situation made Spanish universities to be concerned about the language competences in technical English for civil engineering students. Consequently, Spanish universities are adapting their study programs in order to make their students more competitive and ambitious with respect to their future careers in the current global world.

The scarce number of classes taught in English in the Spanish civil engineering degrees is based on different reasons: (1) Historical protectionism of Spanish in the Spanish society. (2) Low historical unemployment rate among Spanish civil engineering professionals that allowed them to develop their professional careers in Spain. (3) Lack of a clear strategy on teaching in a foreign language in Spanish civil engineering schools. In most cases, the offer has included only those classes suggested by the professors themselves, but the schools rarely stimulate them to do so by compensating the extra effort that involves the preparation. (4) Reticence of students to be evaluated in a foreign language, especially in technical degrees. In fact, traditionally, students preferred that the core classes were taught in Spanish, which in most cases limited teaching in English in the other non-core classes.

In general, current Spanish civil engineering students have studied English for at least 6 years at secondary school, and some of them for 12 years since primary school. They are even required to obtain a B1 level in order to graduate from their undergraduate studies and to access the graduate studies. However, some researches show that students graduate with a limited level of English (Collins et al., 2000; Gömleksi'z, 2007; Ward, 2009), and that much more has to be done if we are to debate, do business, or have a regular conversation/negotiation with them in this language.

The students' own perspective of their education is also changing radically, as they are becoming more aware of the importance of English in order to develop their professional career. In fact, the number of applications to participate in exchange programs with foreign institutions (i.e. ERASMUS, LEONARDO, SENECA, or IAESTE) increases yearly in practically all bachelor degrees. Yet a large number of these applications are dismissed at the receiving institutions because of the lack of the required level of English on the part of the applicants. 
In this sense, some Spanish degrees in civil engineering (i.e. the polytechnic universities of Catalonia, Valencia, or Madrid) offer a class in "Technical English" where the student earns complementary English competences for their future professional profile. Some universities even require accrediting a B2 level to be able to enroll in this course, which, at the same time, is mandatory to graduate from the undergraduate program. This course usually develops students' writing skills (they must learn technical vocabulary and write technical reports), listening skills (classes are given in English and technical videos in English are used as well), and reading skills (they read technical documents and reports). However, the class does not cover all the skills that the student would need in the labor market, since there is rarely enough time and means for students to practice the English speaking skills under the supervision of professors. Therefore, an English integral education is needed with training activities complementary to the Technical English course.

Three issues are raised in the case of the Technical English course. Firstly, the vocabulary of this class is out of context and it is taught all at once without being applied in the different areas of civil engineering. Secondly, the very limited length of the class (merely four months or 4.5/6 ECTS) does not guarantee that students learn the required minimum vocabulary to practice engineering. Thirdly, this class is usually conducted by language specialists and not by civil engineers that could be closer to the engineering needs in the professional sphere, not being able to design specific exercises focused to the students' future professional requirements (Collins et al., 2000).

Other strategies or experiences aiming at improving the English language proficiency for civil engineering students are hard to find, in spite of the above-mentioned importance of this skill. Some universities of English speaking countries offer specialized courses to help international students with technical engineering concepts in English, like the Imperial College $^{1}$ in the UK or the University of Adelaide ${ }^{2}$ in Australia (Missingham, 2006). The Institution of Civil Engineers in the UK holds "Lunch and Learn webinars"3 of 30-45 minutes on current civil engineering topics, focused on "continuing professional development" for professionals; while the London School of Economics celebrates "Lunchtime Lectures" ${ }^{4}$ covering political, economic, financial, legal, and social issues. Brown University, in the US, offers weekly workshops and "brown bag" conversation "Seminars for English Language Learners"5 where student-selected news articles trigger

\footnotetext{
${ }^{1}$ http://www.imperial.ac.uk/academic-english/undergraduate-and-exchange-students/

${ }^{2}$ https://www.adelaide.edu.au/course-outlines/104829/1/sem-1/

${ }^{3}$ https://www.ice.org.uk/news/lunch-and-learn-webinars-to-aid-your-cpd

${ }^{4}$ http://www.lse.ac.uk/europeanInstitute/events/BREXIT-Lunchtime-Lectures.aspx

${ }^{5}$ https://www.brown.edu/academics/college/support/writing-center/english-second-language/english-language-learners
} 
discussions about US culture, idiomatic language, and vocabulary. These seminars are offered during lunchtime and food and refreshments are provided by the university.

Regarding regulated education in non-English speaking countries, some universities offer bilingual degrees in Civil Engineering, while some other offer intensive courses with lexical-semantic, syntactic, pragmatic and phonological contents. Generally, BSc civil engineering education in non-English speaking countries is mostly taught in the mother language. However, due to the necessity of improving the students English skills, some universities are inserting contents in a foreign language, mainly English (i.e. Politecnico di Torino, Italy) or even specific language education (i.e. École des Ponts ParisTech, France). Exceptions have been found in Eastern-European countries, where the study programme can be fully followed in English (i.e. Politehnica University of Bucharest or University of Warsaw).

A different scenario develops in MSc civil engineering education. The most representative universities in Sweden and Poland offer these studies totally in English. On the contrary, Spain, Italy, Germany, or France tend to maintain the mother language in most of their master programmes, although English has a higher presence than in their undergraduate studies, with percentages that can reach up to $30 \%$. This fact highlights the need of a softer transition from an education in the mother tongue to an education in English, which in most of the cases takes place with the access to master studies.

The urgent internationalization of students and future professionals demanded by the current labor market has thus contributed to the increase in the students' willingness to study core classes in English in Spain. However, students still maintain a certain reluctance to enroll in an engineering class taught in English because it can become a challenging obstacle if they do not possess an adequate level of English. In addition, students find another drawback when facing extremely condensed engineering classes (due to the degrees' homogenization by the Bologna Process) in a foreign language. This situation places the students in an important dilemma. On the one hand, they are aware of the importance of learning in English and want to make the effort to study the class in this language. On the other hand, they do not dare to take the class in English because they do not know if they will be able to follow it with their current knowledge of English.

Despite the great acceptance of this class by the students in their respective universities, the UCLM School of Civil Engineering does not have a "Technical English" class. This fact significantly disturbs the students' technical English education and makes them less competitive in the current labor market. Aware of this problem, and taking advantage of the effort being made by the Vice Chancellor of International Relations to internationalize the UCLM, the UCLM School of Civil Engineering has outlined a strategy to improve the competitiveness of our students at an international level. This strategy includes the 
following actions: (1) to improve students' self-confidence so that they can successfully face classes and speaking in English; (2) to develop students' communicative skills in English (this is key to the School as it applies a project-based learning methodology); (3) to encourage critical thinking, discussion, and participation among students; (4) to increase the number of classes taught in English; and (5) to promote the creation of new ERASMUS agreements and double degrees with foreign universities.

\section{2. "Lunch\&Movies", honing technical English skills of future civil engineers}

The present teaching and learning experience is a first step to respond to the actions described above. The main objective of this project is to develop students' communicative skills (both listening and speaking) in English, encouraging discussion, participation and their confidence to speak English in public. The proposed innovative training activities have the purpose to reinforce the skills of all the subjects of the Civil Engineering educational program. For this reason, it is suggested an entertaining and fun learning method outside of the classroom and away from regular evaluation systems through voluntary training activities in sessions called "Lunch\&Movies". These sessions were accommodated throughout the 2015-2016 academic year (usually once every month) in agreement with the students' availability. The sessions can be classified in:

1. Cine-Forum on Technical Civil Engineering topics. This activity is developed in sessions during lunchtime with an average duration of 75 minutes and have two clearly differentiated parts. During the first half of the session, attendees watch a 20-to-40 min video on one of the main areas of civil engineering (urban planning, transportation, hydraulics, geotechnics, environment, technical drawing, and materials and structures) in English. Professors of the different areas are in charge of organizing each session and preparing a "viewing guide" with key technical vocabulary and related questions for debate. In the second half of the session, students are divided in groups of 3-4 people (with a similar level of English) led by one or two professors for debating about the viewed video. The groups, under the guidance of the assigned professor, first identify the meaning of different technical terms that appeared during the viewing, followed by a debate in English about some issues related to the video. At the end of each session, a representative from each group is responsible for presenting their main conclusions to the rest of the class. 
2. Role playing on real professional situations. This activity is based on a "role play" game, a technique widely used in MBA studies. These sessions improve both the students' empathy and their communicative skills in professional situations. During each session, and guided by professors as well, students are divided into groups of 3-4 people. Each member of these groups is assigned a different role of a hypothetical professional situation. For example, if a problem occurred during the construction process of the Panama Canal, the different roles of a group of 4 people could be: a member of the local administration, a member of the construction firm, a member of the protection agency of birds, and the investor.

In order to document the students' learning process, sessions might be recorded and analyzed by professors afterwards. Then, students receive feedback on their speaking exercise as it is a key aspect if we are committed to improve student English skills (Kuhn and Vaught-Alexander, 1994; Berthouex, 1996). At the end of the academic year, the students complete an online survey about what they have learnt and about the usefulness of the sessions. This evaluation may also be supplemented with pre-and post-participation level tests so the groups are composed by professors and students with a similar level of English, regardless of the academic year they are in. In this sense, the project achieves three paramount objectives: first, students feel more comfortable and get over their shyness about speaking English in public; second, students from different years and studies (undergraduate and graduate) get to know each other; and third, it fosters collaboration between professors and students.

Before the project started, the students filled an online survey to assess their perception of the quantity and level of English taught at the UCLM School of Civil Engineering. In total, 135 students replied ( $85 \%$ of total), showing the high interest on this issue. Some of the results of the surve are the following:

- Students agreed on the importance of technical English for their future career.

- The students' level of English is far from that required by other Spanish schools of civil engineering: in average, B 1 or lower; and B2 is only obtained by $11 \%$ of the students. The higher level is clearly attained in the Master degree, which is explained by the fact that a B1 certificate is required in the admission process.

- The majority of students (51\%) would be able to understand less than half of an engineering class taught in English. In the master degree, this figure is of $80 \%$.

- The main reason that leads students to choose classes in Spanish is "Fear of not being able to follow classes in English", and not "Easiness of the class in Spanish". 
Romero de Ávila, V.; Díaz, S.; Asensio, L.; Lozano, J.A.; Moyano, A.; Porras, R.; Poveda, E.; Ruiz, R.; Sánchez, D.; Sánchez-Cambronero, S.; Tarifa, Manuel A.; Yustres, A; Castillo, C.

- $\quad$ The majority of students have a lack in skills that are difficult to train in regular classes (speaking and talking) and would require complementary activities in order to develop these skills. However, they feel more comfortable reading and writing.

- The majority of students $(85 \%)$ would be willing to attend the lunchtime complementary activities proposed by this project.

This project aims to develop and hone different skills related with the learning and improvement of a foreign language for Spanish civil engineering students:

- $\quad$ To improve the ability of the students to understand the technical vocabulary of the main areas in civil engineering, as well as to develop advanced aspects in English. In spite of a general knowledge of the English language, the technical vocabulary and expressions will be essential in the students' future careers.

- $\quad$ To improve the students' ability to speak fluently in English, as well as, the ability to synthesize ideas and express them correctly.

- $\quad$ To improve the ability to negotiate in English. After finishing the Bachelor Degree in Civil Engineering, they will face situations in which they should be able to discuss and express their opinions correctly in English.

- $\quad$ To improve the students' ability to understand lectures and technical videos in English, not only contributing to learn technical English, but also to expand the knowledge related with the civil engineering environment.

- Finally, the students should have the ability to work abroad since the scope today of civil engineers is set worldwide (Gömleksi $\mathrm{z}, 2007$ ).

\section{Conclusions}

This paper presents an innovative project seeking to strengthen Spanish civil engineers English skills through an informal way of learning. The project proposes optional training activities that allow students to develop skills that can rarely be worked in classrooms (i.e. speaking, negotiating and conversing in English), encouraging debate, participation and the confidence of students to speak in public. These activities have the purpose to reinforce the skills of all the subjects of the Civil Engineering educational program. In this sense, an entertaining and fun learning process outside the classroom and far from traditional evaluation systems is proposed through activities organized in two types of sessions.

First, cine-forum on technical civil engineering topics, where students watch a movie or a lecture on one of the main areas of civil engineering (urban planning, transportation, hydraulics, geotechnics, environment, technical drawing, and materials and structures) in English. After the viewing, students work in small inter-cohort groups composed by students from different courses and a guiding professor. These groups first identify the 
meaning of different technical terms that appeared during the viewing, and subsequently debate in English on different questions related to the video. Second, role playing on real professional situations, where students train both their empathy and their communicative and negotiation skills. During each session students are also divided into groups guided by a professor, and each member is assigned a role of a hypothetical professional situation.

This teaching and learning experience aims at improving the students' speaking and communicative skills in English and thus increasing the students' self-confidence so they demand engineering classes in English. The project increases the technical vocabulary in English in the main areas of civil engineering and provides a broader engineering knowledge on concepts studied in the different classes. In addition, the students are also introduced to the use of audio-visual material for language learning, increasing their listening skills in English by being exposed to different accents that could be needed in their professional career when working with people of different nationalities (Dai and Goodrum, 2011). In this sense, the project encourage teamwork and trains the students' social skills for communication and searching of agreement, developing their critical thinking and healthy respect for different opinions. The project also improves the students' educational mobility in study abroad exchange programs, as international experience in engineering is warmly welcomed by current global engineering firms (Gömleksi z, 2007).

Finally, regarding the UCLM School of Civil Engineering, the project encourages collaboration between the different research areas, it helps attracting more international students and achieve new international exchange agreements with other institutions, making the UCLM Bachelor Degree in Civil Engineering much more attractive to future students.

\section{References}

Berthouex, P. M. (1996).Honing the writing skills of engineers. Journal of Professional Issues in Engineering Education and Practice, 122(3), 107-110.

Collins, R., Li, S., and Cheung, D. (2000). Language professionals in engineering faculty: cross-cultural experience. Journal of Professional Issues in Engineering Education and Practice, 126(1), 32-34.

Dai, J. and Goodrum, P. M. (2011). Differences in perspectives regarding labor productivity between Spanish- and English-speaking craft workers. Journal of Construction Engineering and Management, 137(9), 689-697.

Gömleksi z, M. N. (2007). Effectiveness of cooperative learning (jigsaw II) method in teaching English as a foreign language to engineering students (Case of Firat University, Turkey). European Journal of Engineering Education, 32(5), 613-625.

Kuhn, M. R. and Vaught-Alexander, K. (1994). Context for writing in engineering curriculum. Journal of Professional Issues in Engineering Education and Practice, 120(4), 392-400. 
Romero de Ávila, V.; Díaz, S.; Asensio, L.; Lozano, J.A.; Moyano, A.; Porras, R.; Poveda, E.; Ruiz, R.; Sánchez, D.; Sánchez-Cambronero, S.; Tarifa, Manuel A.; Yustres, A; Castillo, C.

Missingham, D. (2006). "The integration of professional communication skills into engineering education." Proceedings of the EDU-COM 2006 International Conference on Engagement and Empowerment: New Opportunities for Growth in Higher Education. Edith Cowan University, Perth Western Australia, 22-24 November 2006.

Ward, J. (2009). A basic engineering English word list for less proficient foundation engineering undergraduates. English for Specific Purposes 28, 170-182. 